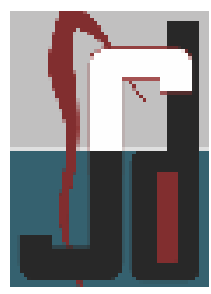

\title{
Review
}

\section{Functional foods and its role in improving oral health}

M.Vikneshan ${ }^{1}$, A.V. Ankola ${ }^{2}$, Anand Hiremath ${ }^{3}$, Mamata Hebbal ${ }^{4}$, Suganya.M ${ }^{5}$

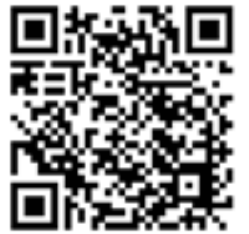

ABSTRACT : Functional foods are foods or dietary components that may provide a health benefit beyond basic nutrition. Biologically active components in functional foods may impart health benefits or desirable physiological effects. Oral diseases are lifestyle related and diet plays a major role. Various foods are found to have role in improving oral health. In this article the most explored functional foods like tea, grapes, coffee, garlic and its role in oral health are discussed. Tea (Camellia sinensis) and is the most popular beverage consumed by human society worldwide, second only to water. Tea has anti-cariogenic potential by inhibiting biofilm formation, acid production and also studies have shown tea has a preventive effect on periodontal disease. Garlic is known for its medicinal property all over the world, it prevents dental caries, periodontal disease. as well as shown positive results in the treatment of Candiidasis. Coffee is another beverage which has preventive effects on dental caries and oral cancer. Grapes are another such functional food which has preventive effects on dental caries, periodontal disease, as well as remineralization potential. These functional foods lack sound evidence to be recommended as part of health care. The people consuming these foods must realize that functional foods are not a "magic bullet" or a panacea for poor health habits. Functional foods can become part of an effective strategy to maximize health and reduce disease risk by addressing all these issues.

Keywords : tea, grapes, garlic, coffee, anti-cariogenic.

\section{INTRODUCTION}

Oral health is a state of the mouth and associated structures where disease is contained, future disease is inhibited, the occlusion is sufficient to masticate food and the teeth are of a socially acceptable appearance.(1) Oral health is integral to general health and essential for well being. It implies being free of chronic oro-facial pain, oral and pharyngeal cancer, oral lesions and other diseases and disorders that affect the oral, dental and craniofacial tissues, collectively known as craniofacial complex. The craniofacial complex allows us to speak, smile, touch, smell, taste, chew, and swallow and to cry out in pain. It provides protection against microbial infections and environmental threats. Oral diseases restrict activities in school, at work and at home causing millions of school and work hours to be lost. Moreover, the psychosocial impact of these diseases often significantly diminishes quality of life.

Despite great achievements in oral health of populations globally, problems still remain in many communities around the world. Though many measures are taken at all levels - community and individual levels to maintain oral health, these measures are inadequate in resolving the issues of oral diseases.

Individuals can take actions for themselves and persons under their care to prevent disease and maintain health. With appropriate diet and nutrition, primary prevention of many oral, dental and craniofacial diseases can be achieved. (2)

Functional foods are one such aspect of primary prevention which can be included in the arsenal of fighting against the oral diseases. Functional foods are foods or dietary components that may provide a health benefit beyond basic nutrition. The individual can take greater control of health through the food choices they make, knowing that some foods can provide specific health benefits. Examples can include fruits and vegetables, whole grains, fortified or enhanced foods and beverages, and some dietary supplements. Biologically active components in functional foods may impart health benefits or desirable physiological effects. 
Functional attributes of many traditional foods are being discovered, while new food products are being developed with beneficial components.(3) The underlying rationale for such foods is that, oral diseases are lifestyle related with diet playing a major role.

There are various foods, which can be classified as functional foods. In this article, we discuss about the foods most widely studied, as listed below and its role to improve oral health
1. Tea
2. Garlic
3. Coffee
4. Grapes

\section{Tea as functional food in oral health}

Tea is an aqueous infusion of dried leaves of the plant Camellia sinensis L.(family The aceae) and is the most popular beverage consumed by human society worldwide, second only to water. The chemical composition of tea is complex: polyphenols, catechins, caffeine, amino acids, carbohydrates, protein, chlorophyll, volatile compounds, fluoride, minerals, and other undefined compounds. ${ }^{(4)}$ The fluoride content of green tea ranges between 1 and 2 parts per million. The role of green tea in oral health is found in the literature as animal ${ }^{(5,6)}$ studies, in vitro studies $^{(7,8)}$ and few in vivo studies ${ }^{(9,10,11)}$.

\section{Tea and its anti-cariogenic properties}

The components of tea show various properties to inhibit dental caries. Dental caries is chronic diseases arising from interplay between oral flora, the teeth and dietary factors. The major organisms involved are Streptococcus mutans and S.sobrinus although several other types of bacterias like Lactobacilli and Actinomyces may be involved. Dental caries is formed by three processes, first adhesion of the micro-organism, secondly formation of glycocalyx due to synthesis of sticky glucan by action of bacterial enzyme and third accumulation of biofilm (plaque), inside which constant acid production by bacterias occur, thus demineralising the enamel. ${ }^{(12)}$

\section{Mode of action}

Tea and its various components shown to have potential anti-cariogenic properties, interfering the steps in caries formation.

\section{Inhibition of biofilm formation}

A study conducted by Hassani et al ${ }^{(13)}$ evaluated the efficacy of semi fermented and non fermented Camellia sinensis extracts (Black and Green tea) and comparison between them against Streptococcus mutans ATCC 25175, S. mitis ATCC 9811 and S. sanguis ATCC 10556 that are responsible for dental caries and bacteremias following dental manipulations. Minimum. Concentration of $1 \mathrm{mg} / \mathrm{mL}$ of semi fermented tea extract was completely biofilm inhibitor but biofilm formation by these bacteria was seen 7 days after treatment with $1 \mathrm{mg} / \mathrm{mL}$ of non fermented Camellia sinensis on glass beads and BIC for oral streptococci treated with this extract was 1.5, 2.5 $\mathrm{mg} / \mathrm{mL}$ of semi fermented and $3 \mathrm{mg} / \mathrm{mL}$ of non fermented extracts had bactericidal effect on these bacteria. They concluded that semi fermented and non fermented Camellia sinensis extracts were able to prevent growth of oral streptococci. Therefore dental caries significantly reduce and the efficiency of semi fermented tea was higher due to rich content of volatile components rather than non fermented extracts.

Otale et $\mathrm{al}^{(14)}$ conducted a study in rats, in which the extracts from Japanese green tea inhibited the adherence of S.mutans.

\section{Inhibition of acid production}

In a study conducted by Hirasawi et al (15), they examined the inhibition of acid production from dental plaque and mutans streptococci by epigallocatechin gallate (EGCg), one of the green tea catechins. The effect of EGCg solution on dental plaque $\mathrm{pH}$ was investigated by using a rinse containing of $2 \mathrm{mg} / \mathrm{ml}$ EGCg. The $\mathrm{pH}$ values of plaque samples were significantly higher after treatment with catechin than after treatment with water. $\mathrm{EGCg}$ inhibited $\mathrm{pH}$ fall when cariogenic bacteria grown in medium with or without sucrose were incubated with sugar. 
In medium without sucrose, cultured cells were killed time-dependently by EGCg treatment. EGCg and epicatechin gallate inhibited lactate dehydrogenase activity much more efficiently than epigallocatechin, epicatechin, catechin or gallocatechin. These results suggest that EGCg is effective in reducing acid production in dental plaque and mutans streptococci.

\section{Anti-streptococcal activity}

Few studies have shown that extracts of Green tea and Black tea were inhibitory and bactericidal against S.mutans and S.sobrinus. the minimal inhibitory concentrations ranged from 50 $500 \mathrm{mg} / \mathrm{L}$ from these studies.

In a study conducted by Xu et al (16) investigated the biological effect of EGCg on the virulence factors of $\mathrm{S}$. mutans associated with its acidogenicity and acidurity. They found that EGCg inhibited growth of S. mutans planktonic cells at an MIC of $31.25 \mu \mathrm{g} / \mathrm{ml}$ and a minimal bactericidal concentration (MBC) of $62.5 \mu \mathrm{g} / \mathrm{ml}$. $\mathrm{EGCg}$ also inhibited $\mathrm{S}$. mutans biofilm formation at $15.6 \mu \mathrm{g} / \mathrm{ml}$ (minimum concentration that showed at least $90 \%$ inhibition of biofilm formation) and reduced viability of the preformed biofilm at 625 $\mu \mathrm{g} / \mathrm{ml}$ (sessile $\mathrm{MIC}_{80}$ ). EGCg at sub-MIC levels inhibited acidogenicity and acidurity of S. mutans cells. Analysis of the data obtained from real-time PCR showed that EGCg significantly suppressed the ldh, eno, atpD, and aguD genes of S. mutans UA159. Inhibition of the enzymatic activity of $\mathrm{F}_{1} \mathrm{~F}_{0}$-ATPase and lactate dehydrogenase was also noted (50\% inhibitory concentration between 15.6 and $31.25 \mu \mathrm{g} / \mathrm{ml}$ ). They suggested that EGCg is a natural anticariogenic agent in that it exhibits antimicrobial activity against $\mathrm{S}$. mutans and suppresses the specific virulence factors associated with its cariogenicity.

\section{Clinical evidence \\ Prevention of periodontal disease}

The potential of tea and its extracts in inhibiting biofilm formation and its anti-bacterial activity, is useful in preventing periodontal disease as well. The clinical study conducted by Kushiyama et $\mathrm{al}^{(11)}$ examined the relationship between green tea consumption and periodontal disease. The intake of green tea was analyzed with parameters like Probing Depth (PD), clinical attachment loss (CAL) and Bleeding On Probing (BOP). They found that intake of green tea was inversely correlated with $\mathrm{PD}, \mathrm{CAL}$ and BOP, thus concluding that Green tea has a preventive role in periodontal disease.

In another study conducted by Awadallah et $\mathrm{al}^{(10)}$, found that $5 \mathrm{~min}$ rinsing with $2 \%$ green tea reduced S.mutans count in plaque and saliva also salivary and plaque $\mathrm{pH}$ as well as Gingival Bleeding Index.

\section{Prevention of dental caries}

In another study by Koyama et $\mathrm{al}^{(9)}$, examined the relationship between green consumption and tooth loss. They found that consumption of one or more than cup of green tea every day significantly reduced the odds of tooth loss.

\section{Garlic and its role in oral health}

Garlic has been used medicinally throughout human history. Allicin is considered the most therapeutic constituent of garlic. Allicin is proposed to be having anti-microbial activity.

\section{Anti-cariogenic and in prevention of periodontal disease}

A study conducted by Bachrach et al ${ }^{(17)}$ tested the antimicrobial activity of garlic allicin on oral pathogens associated with dental caries and periodontitis. They found that Allicin was effective against all the tested bacteria. Streptococcus mutans, S. sobrinus, and Actinomyces oris was inhibited by an allicin concentration of $600 \mu \mathrm{g} /$ $\mathrm{mL}$ or higher. Gram-negative periopathogenic species Aggregatibacter actinomycetemcomitans and Fusobacterium nucleatum was inhibited by a minimum allicin concentration of $300 \mu \mathrm{g} / \mathrm{mL}$. They also found that Porphyromonas gingivalis, an anaerobic, gram-negative pathogen and the bacterium most associated with chronic periodontitis, demonstrated the lowest sensitivity to allicin $(2,400 \mu \mathrm{g} / \mathrm{mL})$. Live/dead staining followed by analysis with confocal laser scanning microscopy revealed that allicin was bactericidal to S. mutans grown in mature biofilms. However, this bactericidal effect was reduced as biofilm 
depth increased

In another study conducted by Groppo et $\mathrm{al}^{(18)}$, the antimicrobial activity of two garlic clones' (1: purple and 2: white) crude extracts against oral microbiota was tested both invivo and invitro. Mouthwash containing garlic extracts were used for 5 weeks and found reduced salivary levels of streptococci was observed after 2 weeks at the end of mouthwash use. The in-vivo showed that MIC(Minimum inhibitory concentration) ranging from 0.5 to $32.0 \mathrm{mg} \mathrm{ml}^{-1}$ for clone 2 and from 8 to $64.0 \mathrm{mg} \mathrm{ml}^{-1}$ for clone 1 . MBC Minimum Bactericidal concentration) ranged from 1.0 to $128.0 \mathrm{mg} \mathrm{ml}^{-1}$ and from 8.0 to $128.0 \mathrm{mg} \mathrm{ml}^{-1}$ regarding clones 2 and 1 respectively.

Another study by Chavan et $a^{(19)}$ confirmed the effectiveness of garlic extract in reducing salivary Streptococcus mutans. In this study they found that MIC was 3\% and reduced S.mutans levels in garlic mouthwash group after 7 days use.

\section{Mechanism of action}

1. Allicin inhibits the proteases of P. gingivalis, including the arginine and lysine gingipains known as major virulence factors of this organism.

2. Allicin inhibits the growth of S.mutans thereby reducing the risk of dental caries. But clinical evidence is lacking.

\section{In Candidiasis treatment}

A randomized controlled trial was conducted by Sabitha et $\mathrm{al}^{(20)}$ in which topical application of garlic paste for 14 days was found to be as effective as that of clotrimazole solution in suppressing clinical signs of oral candidiasis.

\section{Coffee and its role in oral health}

Coffee is the second most commonly consumed hot beverages worldwide. However, its role in oral health is least studied or published in the literature.

\section{In caries}

A study conducted by Papeti et $\mathrm{al}^{(21)}$ found that coffee protects tooth surfaces against Streptococcus mutans colonization. They showed that barley coffee (BC), a beverage made from roasted barley, interferes with $\mathrm{S}$. mutans adsorption to hydroxyapatite (HA), and identified its antiadhesive components. The effects of sublethal concentrations of $\mathrm{BC}$ on the adhesion of S. mutans to saliva-coated HA beads were and found significant inhibition of S.mutans.

\section{In cancer}

In a meta-analysis by Dakak ${ }^{(22)}$, it was shown that caffeinated coffee was inversely associated with risk of oral cancer. Thus, implying decaffeinated coffee may have a protective effect on oral cancer.

In another case-control study conducted by Galeone et $\mathrm{al}^{(23)}$, they found that coffee consumption was inversely associated with oral cancer risk. The biological explanation given was high antioxidant properties of coffee beverages.

\section{Grapes and its role in oral health}

Raisins are dried grapes, fruits of Vitis vinifera l. (vitaceae). As a popular snack food, raisins contain polyphenols, flavonoids, iron, minerals, potassium, calcium, and certain B vitamins that may benefit overall human health. Raisins are cholesterol and fat free, rich in antioxidants, and a good source of fiber (24).

The antimicrobial compounds present in raisins capable of suppressing growth and/ or virulence properties of oral pathogens have been fractionated and identified. The derivatives from grapes like oleanolic acid, oleanolic aldehyde, 5-(hydroxymethyl)- 2-furfural and rutin demonstrated growth inhibitory activity against 2 oral pathogens, the cariogenic S. mutans and the periodontopathic Porphyromonas.gingivalis.

Grape seed extract (GSE) is a rich source of PA, which has been reported to strengthen collagenbased tissues by increasing collagen cross-links Proanthocyanidin (PA commonly used as natural antioxidants and free-radical scavengers, PA has been proven to be safe in various clinical 
applications and as dietary supplements ${ }^{(24)}$.

\section{Remineralization potential of grapes}

Xie et al. (25) performed a study to examine the effect of grape seed extract (GSE) on the remineralization and demineralization of the collagen-rich root tissue of human teeth. Teeth fragments obtained from the cervical portion of the root were stored in a demineralization solution for $96 \mathrm{~h}$ at $37^{\circ} \mathrm{C}$ to induce artificial root caries lesions. The fragments were then divided into 3 treatment groups: $6.5 \%$ GSE, $1000 \mathrm{mg} / \mathrm{L}$ fluoride $(\mathrm{NaF})$, and an untreated control. The demineralized samples were $\mathrm{pH}$-cycled through treatment solutions, acidic buffer, and neutral buffer for 8 d at 6 cycles/d. Results obtained from this study showed that treatment with GSE was also found to increase the microhardness of the lesions compared with the untreated control group $(\mathrm{P}<$ 0.05). Polarized light microscopy data revealed a significantly thicker mineral precipitation band on the surface layer of the GSE-treated lesions, which was further confirmed by con-focal laser scanning microscopy. The data supported the fact that GSE positively affected the demineralization and/or remineralization processes of artificial root caries lesions, most likely through a different mechanism than that of fluoride. GSE may contribute to mineral deposition on the superficial layer of the lesion and may also interact with the organic portion of the root dentin through PA-collagen interaction, thereby stabilizing the exposed collagen matrix. GSE may be a potential adjunct or alternative to fluoride in the treatment of root caries during minimally invasive therapy.

\section{Conclusion}

Many functional foods are found to be beneficial in prevention of oral diseases and thus shows a promise for improving public health. Although these benefits are not supported strongly by scientific evidence, to recommend these foods as dietary supplements. The functionalities of these functional foods should be based on sound and accurate scientific criteria, by conducting rigorous studies of safety and efficacy. Interactions with other dietary components and potential adverse interactions with other drugs/ pharmaceutical agents must be clearly imparted. The people consuming these foods must realize that functional foods are not a "magic bullet" or a panacea for poor health habits. Thus, they should be educated about the implied benefits of these foods, and must realize that there is no consistent regulation in the functional foods area.

Diet is only one aspect of a comprehensive lifestyle approach to good health, which should include regular exercise, tobacco avoidance, stress reduction, maintenance of healthy body weight and other positive health practices (26). Functional foods can become part of an effective strategy to maximize health and reduce disease risk by addressing all these issues.

\section{References}

1. Slade, G.D. Measuring oral health and quality of life. Proceedings of a conference held June 13, 172 (1996).

2. US Department of Health and Human Services. Oral Health in America: A Report of the Surgeon General-Executive Summary . Rockville, MD: US Department of Health and Human Services, National Institute of Dental and Craniofacial Research, National Institutes of Health, 2000.

3. International food information council foundation. Functional foods (Internet ) 2010.Available from http://www.foodinsight.org/Content/3842/Final\%20 Functional $\% 20$ Foods $\% 20$ Backgrounder.pdf.

4. Graham HN. Green tea composition, consumption, and polyphenol chemistry. Prev Med 1992;21:334.

5. Ooshima $\mathrm{T}$, Minami $\mathrm{T}$, Matsumoto $\mathrm{M}$, et al. Comparison of the cariostatic effects between regimens to administer oolong tea polyphenols in SPF rats. Caries Res 1998;32:75

6. Sakanaka S, Aizawa M, Kim M, et al. Inhibitory effects of green tea polyphenols on growth and cellular adherence of an oral bacterium, Porphyromonas gingivalis. Biosci Biotech Biochem 1996; 60:745

7. Rasheed A, Haider M. Antibacterial activity of Camellia sinensis extracts against dental caries. Arch Pharm Res. 1998 Jun;21(3):348-52.

8. You SQ. [Study on feasibility of Chinese green tea polyphenols (CTP) for preventing dental caries]. Zhonghua Kou Qiang Yi Xue Za Zhi. 1993 Jul;28(4):197-9, 254. 
9. Koyama Y, Kuriyama S, Aida J, Sone T, Nakaya N, Ohmori-Matsuda K, Hozawa A,

10. Tsuji I. Association between green tea consumption and tooth loss: cross-sectional results from the Ohsaki Cohort 2006 Study. Prev Med. 2010 Apr;50(4):173-9. Epub 2010 Jan 25.

11. Awadalla HI, Ragab MH, Bassuoni MW, Fayed MT, Abbas MO. A pilot study of the role of green tea use on oral health. Int J Dent Hyg. 2011 May;9(2):110-6. doi: 10.1111/j.1601-5037.2009.00440.x

12. Kushiyama M, Shimazaki Y, Murakami M, Yamashita Y. Relationship between intake of green tea and periodontal disease. J Periodontol. 2009 Mar;80(3): 372-7.

13. Hamilton-Miller JM. Anti-cariogenic properties of tea (Camellia sinensis). J Med Microbiol. 2001 Apr;50(4):299-302. Review.

14. Hassani AS, Amirmozafari N, Ordouzadeh N, Hamdi K, Nazari R, Ghaemi A. Volatile components of Camellia sinensis inhibit growth and biofilm formation of oral streptococci in vitro. Pak J Biol Sci. 2008 May 15;11(10):1336-41.

15. Otake S, Makimura M, Kuroki T, Nishihara Y, Hirasawa M. Anticaries effects of polyphenolic compounds from Japanese green tea. Caries Res. 1991;25(6):438-43.

16. Hirasawa M, Takada K, Otake S. Inhibition of acid production in dental plaque bacteria by green tea catechins. Caries Res. 2006;40(3):265-70.

17. $\mathrm{Xu} \mathrm{X}$, Zhou $\mathrm{XD}, \mathrm{Wu} \mathrm{CD}$. The tea catechin epigallocatechin gallate suppresses cariogenic virulence factors of Streptococcus mutans. Antimicrob Agents Chemother. 2011 Mar;55(3):1229-36. Epub 2010 Dec 13

18. Bachrach G, Jamil A, Naor R, Tal G, Ludmer Z, Steinberg D. Garlic allicin as a potential agent for controlling oral pathogens. J Med Food. 2011 Nov;14(11):1338-43.
19. Groppo FC, Ramacciato JC, Motta RH, Ferraresi PM, Sartoratto A. Antimicrobial activity of garlic against oral streptococci. Int J Dent Hyg. 2007 May;5(2): 109-15.

20. Chavan SD, Shetty NL, Kanuri M. Comparative evaluation of garlic extract mouthwash and chlorhexidine mouthwash on salivary Streptococcus mutans count - an in vitro study. Oral Health Prev Dent. 2010;8(4):369-74.

21. Sabitha P, Adhikari PM, Shenoy SM, Kamath A, John R, Prabhu MV, Mohammed S, Baliga S, Padmaja U. Efficacy of garlic paste in oral candidiasis. Trop Doct.2005 Apr;35(2):99-100.

22. Papetti A, Pruzzo C, Daglia M, Grisoli P, Bacciaglia A, Repetto B, Dacarro C, Gazzani G. Effect of barley coffee on the adhesive properties of oral streptococci. $\mathrm{J}$ Agric Food Chem. 2007 Jan 24;55(2):278-84.

23. Al-Dakkak I. Tea, coffee and oral cancer risk. Evid Based Dent. 2011;12(1):23-4.

24. Galeone C, Tavani A, Pelucchi C, Turati F, Winn DM, Levi F, Yu GP, Morgenstern H, Kelsey K, Dal Maso L, Purdue MP, McClean M, Talamini R, Hayes RB, Franceschi S, Schantz S, Zhang ZF, Ferro G, Chuang SC, Boffetta P, La Vecchia C, Hashibe M. Coffee and tea intake and risk of head and neck cancer: pooled analysis in the international head and neck cancer epidemiology consortium. Cancer Epidemiol Biomarkers Prev. 2010 Jul;19(7):1723-36.

25. Wu CD. Grape products and oral health. J Nutr. 2009 Sep;139(9):1818S-23S. Epub 2009 Jul 29. Review.

26. XIE, Q., BEDRAN-RUSSO, A. K. \& WU, C. D. 2008. In vitro remineralization effects of grape seed extract on artificial root caries. Journal of dentistry, $36,900-906$.

27. Hasler CM. Functional foods: benefits, concerns and challenges-a position paper from the american council on science and health. J Nutr. 2002 Dec; 132(12): 3772-81.Ulii intis cora deor atifent eatinte, etimiu 


\section{Address of Correspondence}

Dr. Vikneshan.M,

Department of Public Health Dentistry,

Indira Gandhi institute of Dental Sciences, Pondicherry.

E-mail:drvikneshan@gmail.com

$\mathrm{Ph}:$ 91-9500520798.

\section{Authors:}

${ }^{1}$ Senior Lecturer, Department of Public Health Dentistry, Indira Gandhi institute of Dental Sciences, Pondicherry.

${ }^{2}$ Professor \& Head, Department of Public Health Dentistry, KLE VK Institute of Dental Sciences, Belgaum

${ }^{3}$ Senior Lecturer, Department of Public Health Dentistry, Al Badar Rural Dental College, Gulbarga

${ }^{4}$ Professor, Department of Public Health Dentistry, KLE VK Institute of Dental Sciences, Belgaum.

${ }^{5}$ Senior Lecturer, Department of Pedodontics and Preventive Dentistry, Indira Gandhi Institute of Dental Sciences, Pondicherry

\section{How to cite this article :}

M.Vikneshan, A.V. Ankola, Anand Hiremath, Mamata Hebbal, Suganya.M, Functional foods and its role in improving oral health. Journal of Scientific Dentistry, 2016;6(1):13-19

Source of Support : Nil, Conflicts of Interest : None declared 